\title{
(+)-Catechin protects dermal fibroblasts against oxidative stress-induced apoptosis
}

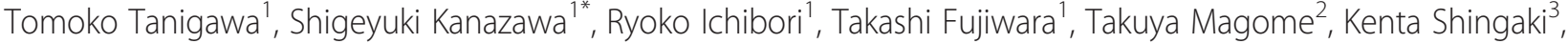 \\ Shingo Miyata ${ }^{4}$, Yuki Hata ${ }^{1}$, Koichi Tomita', Ken Matsuda ${ }^{5}$, Tateki Kubo ${ }^{1}$, Masaya Tohyama ${ }^{3}$, Kenji Yano ${ }^{1}$ \\ and Ko Hosokawa ${ }^{1}$
}

\begin{abstract}
Background: Oxidative stress has been suggested as a mechanism underlying skin aging, as it triggers apoptosis in various cell types, including fibroblasts, which play important roles in the preservation of healthy, youthful skin. Catechins, which are antioxidants contained in green tea, exert various actions such as anti-inflammatory, anti-bacterial, and anti-cancer actions. In this study, we investigated the effect of (+)-catechin on apoptosis induced by oxidative stress in fibroblasts.

Methods: Fibroblasts (NIH3T3) under oxidative stress induced by hydrogen peroxide $(0.1 \mathrm{mM})$ were treated with either vehicle or (+)-catechin (0-100 $\mu \mathrm{M})$. The effect of (+)-catechin on cell viability, apoptosis, phosphorylation of c-Jun terminal kinases (JNK) and p38, and activation of caspase-3 in fibroblasts under oxidative stress were evaluated.

Results: Hydrogen peroxide induced apoptotic cell death in fibroblasts, accompanied by induction of phosphorylation of JNK and p38 and activation of caspase-3. Pretreatment of the fibroblasts with (+)-catechin inhibited hydrogen peroxide-induced apoptosis and reduced phosphorylation of JNK and p38 and activation of caspase-3.

Conclusion: (+)-Catechin protects against oxidative stress-induced cell death in fibroblasts, possibly by inhibiting phosphorylation of p38 and JNK. These results suggest that (+)-catechin has potential as a therapeutic agent for the prevention of skin aging.
\end{abstract}

Keywords: Catechin, Fibroblast, Apoptosis, Oxidative stress

\section{Background}

Skin wrinkles and sagging are important factors defining skin youthfulness. Development of methods to reduce skin wrinkles and prevent sagging skin has become an important research topic in aesthetic and anti-aging medicine. Skin wrinkles and sagging are reported to be influenced by the amount of collagen, elastin, and hyaluronic acid [1]. Fibroblasts play a key role in the production of these extracellular matrix components in the skin. Skin aging is the consequence of reduced numbers of fibroblasts, lower levels of extracellular matrix proteins, and decreased skin elasticity and tonus, thereby resulting in the formation of wrinkles [2]. Therefore, maintaining the population of dermal fibroblasts

\footnotetext{
* Correspondence: kanazawa@psurg.med.osaka-u.ac.jp

'Department of Plastic Surgery, Osaka University Graduate School of Medicine, Suita-shi, Osaka, Japan

Full list of author information is available at the end of the article
}

is important for both preventing and treating age-related skin changes.

Oxidative stress has been indicated in a variety of pathological processes, such as atherosclerosis, diabetes, neurodegenerative diseases, and aging. Reactive oxygen species induce DNA damage, intracellular lipid peroxidation, and abnormal protein oxidation reactions, all of which result in cell damage. Oxidative stress also promotes skin aging [3]; it reduces the number of skin fibroblasts by inducing apoptosis and decreasing their regenerative capacity, which in turn leads to increased skin sagging. Therefore, suppression of oxidative stress-induced apoptosis in skin fibroblasts is a potential treatment and prevention strategy for maintaining healthy youthful skin.

Green tea, which is routinely consumed in Japan and China, is widely known as a healthy drink containing various antioxidants, vitamins, and minerals. Catechins, including (-)-epigallocatechin gallate (EGCG), (-)-epigallocatechin 
(EGC), (-)-epicatechin gallate (ECG), and (-)-epicatechin (EC) (Figure 1), account for approximately $10 \%$ of the dry weight of green tea leaves. Catechins are thought to not only possess antioxidant effects to control active oxygen [4-7] but also exert various actions, such as anti-inflammatory [8], antibacterial [9,10], and anti-cancer [11-13] actions.

In this study, we demonstrate that (+)-catechin has an inhibitory effect against oxidative stress-induced apoptosis in fibroblasts, accompanied by suppression of phosphorylation of p38 and c-Jun terminal kinases (JNK), both of which play an important role in intracellular apoptotic signaling induced by oxidative stress.

\section{Methods}

\section{Cell culture}

NIH 3T3 fibroblasts were used for all experiments. Cells were cultured in Dulbecco's Modified Eagle Medium (DMEM; Life Technologies CA, USA) containing 10\% fetal bovine serum (FBS), $100 \mathrm{U} / \mathrm{ml}$ penicillin, and $100 \mu \mathrm{g} / \mathrm{ml}$ streptomycin (Life Technologies) in a humidified incubator at $37^{\circ} \mathrm{C}$ with $5 \% \mathrm{CO}_{2}$. All experiments were performed in triplicate.

\section{Cell viability assay}

Cell survival was determined using the 3-(4,5-dimethylthiazole-2-yl)-2,5-diphenyltetrazolium bromide (MTT) assay
(CellTiter $96^{\circ}$ AQueous One Solution Cell Proliferation Assay; Promega, WI, USA). Fibroblasts were plated at a density of 5,000 cells per well on 96-well plates and incubated for $24 \mathrm{~h}$ in $100 \mu \mathrm{l}$ of DMEM containing $10 \%$ FBS. After incubation with serum-free medium for $24 \mathrm{~h}$, cells were treated for $30 \mathrm{~min}$ with various concentrations of (+)-catechin (0-400 $\mu \mathrm{M}$; Sigma Aldrich, PA, USA), and then subjected to oxidative stress induction with $0.1 \mathrm{mM}$ hydrogen peroxide $\left(\mathrm{H}_{2} \mathrm{O}_{2}\right)$. After $24 \mathrm{~h}, 20 \mu \mathrm{l}$ of One Solution Reagent was added into each well and incubated at $37^{\circ} \mathrm{C}$ for $2 \mathrm{~h}$ in a humidified, $5 \% \mathrm{CO}_{2}$ atmosphere. The production of formazan by viable cells was detected by measuring the absorbance at $490 \mathrm{~nm}$ using a 96-well plate reader.

Another series of experiments were conducted to compare cytotoxicity between (+)-catechin and EGCG. Fibroblasts were treated with various concentrations of (+)-catechin or EGCG (0-400 $\mu \mathrm{M}$; Sigma Aldrich) without $\mathrm{H}_{2} \mathrm{O}_{2}$ for $24 \mathrm{~h}$ and the cells were then subjected to MTT assay.

\section{TUNEL staining}

Apoptosis was determined by terminal deoxynucleotidyl transferase (TdT)-mediated dUTP-biotin nick end labeling (TUNEL) using the In Situ Cell Death Detection Kit TMR Red (Roche, Mannheim, Germany), according to

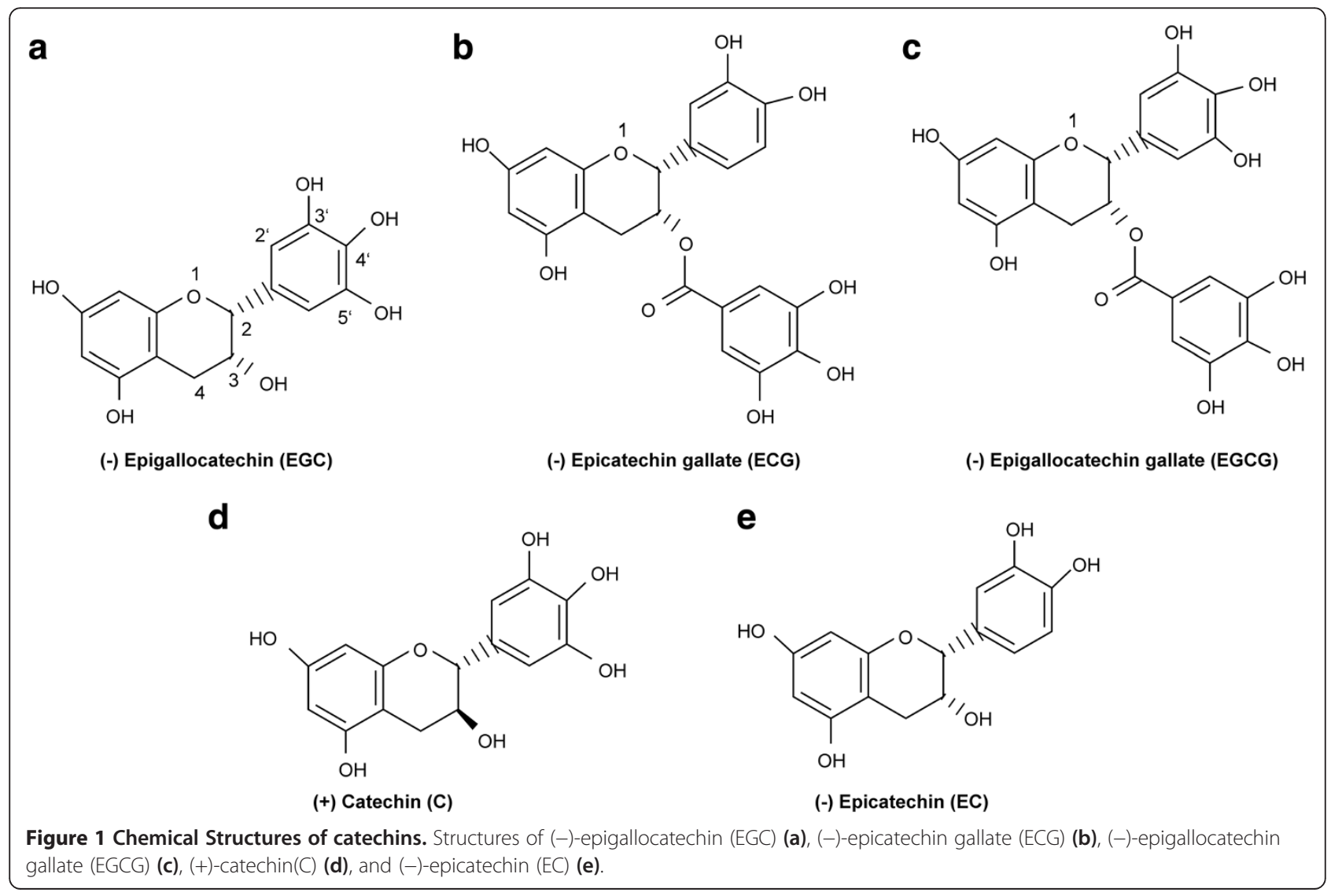


the manufacturer's instructions. In brief, fibroblasts were maintained in DMEM containing 10\% FBS for 2 days and then cultured in serum-free DMEM. Oxidative stress was induced by addition of $0.1 \mathrm{mM} \mathrm{H}_{2} \mathrm{O}_{2}$ prior to treatment with $10 \mu \mathrm{M}(+)$-catechin or vehicle. After $24 \mathrm{~h}$ of incubation with $\mathrm{H}_{2} \mathrm{O}_{2}$ and (+)-catechin or vehicle, cells were fixed with $4 \%$ paraformaldehyde in phosphate-buffered saline (PBS) ( $\mathrm{pH} 7.4$ ) for $60 \mathrm{~min}$ at room temperature, followed by five washes with PBS. Next, permeabilization was performed by incubation with $0.1 \%$ Triton X-100 in PBS for $10 \mathrm{~min}$, and cells were mixed with TUNEL reaction mixtures containing $\mathrm{TdT}$ and tetramethylrhodamine (TMR) red-labeled nucleotides for $1 \mathrm{~h}$. Coverslips were mounted onto slides using VECTASHIELD Mounting Medium with 4',6-diamidino-2-phenylindole dihydrochloride (Vector Laboratories, Peterborough, England). Fluorescence images were taken using a microscope (IX-70; Olympus) equipped with a charge-coupled device camera (CoolSNAP HQ; Nippon Roper, Chiba, Japan). For each experiment, 100 cells were randomly selected, and the percentage of TUNEL-positive cells was measured.

\section{Western blot analysis}

Cultured fibroblasts were serum-starved for $24 \mathrm{~h}$ in serumfree DMEM and then incubated with $10 \mu \mathrm{M}(+)$-catechin for $30 \mathrm{~min}$ prior to oxidative stress induction by $0.1 \mathrm{mM}$ $\mathrm{H}_{2} \mathrm{O}_{2}$. After $\mathrm{H}_{2} \mathrm{O}_{2}$ challenge for $1 \mathrm{~h}$, cells were harvested and lysed in radioimmunoprecipitation assay buffer containing $1 \mathrm{mM} \mathrm{Na}_{3} \mathrm{VO}_{4}, 1 \mathrm{mM} \mathrm{NaF}$, and Protease Inhibitor Cocktail (Roche Diagnostics, Basel, Switzerland) for $20 \mathrm{~min}$ at $4^{\circ} \mathrm{C}$. After centrifugation at $15,000 \times g$ for $15 \mathrm{~min}$ at $4^{\circ} \mathrm{C}$, proteins were separated by sodium dodecyl sulfatepolyacrylamide gel electrophoresis and transferred onto Immobilon-P Transfer Membranes (Millipore Japan, Tokyo, Japan). Membranes were incubated for $60 \mathrm{~min}$ in Trisbuffered saline containing 5\% skim milk and $0.05 \%$ Tween-20 and then blotted with the following primary antibodies at $4^{\circ} \mathrm{C}$ overnight: anti-phospho-JNK (1:1,000), anti-JNK (1:1,000), anti-phospho-p38 (1:1,000), anti-p38 (1:1,000), anti-cleaved caspase-3 (1:200), and anti-caspase-3 antibodies (1:200). All antibodies were purchased from Cell Signaling Technology, MA, USA. Next, membranes were incubated for $1 \mathrm{~h}$ with an anti-mouse or anti-rabbit HRP-linked secondary antibody (1:2,000; Cell Signaling Technology). Reaction products were visualized by chemiluminescence detection using the ECL Western Blotting Detection System (GE Healthcare, Piscataway, NJ, USA). Quantification of relative band densities was performed by densitometry using Image J software (National Institutes of Health, Bethesda, MD, USA).

\section{Statistical analysis}

All data shown are expressed as the mean \pm SE of three independent experiments. Data from each experiment were normalized to the respective control sample. Differences between conditions were analyzed by Student's $t$ test. Multiple-group comparisons were performed using a one-way analysis of variance, followed by Tukey's post hoc test. $\mathrm{P}<0.05$ was considered statistically significant.

\section{Results}

\section{Catechin increases the viability of fibroblasts}

Oxidative stress is known to promote fibroblast cell death [14]. To analyze the effect of $(+)$-catechin on the viability of fibroblasts in response to oxidative stress, cells cultured with various concentrations $(0-100 \mu \mathrm{M})$ of catechin were subjected to oxidative stress induction by $0.1 \mathrm{mM} \mathrm{H}_{2} \mathrm{O}_{2}$. The cell numbers were analyzed after $24 \mathrm{~h}$. Microscopic observation and MTT assay showed that $\mathrm{H}_{2} \mathrm{O}_{2}$ inducedoxidative stress reduced cell viability, whereas $(+)$-catechin suppressed the effect of $\mathrm{H}_{2} \mathrm{O}_{2}$-induced oxidative stress on cell viability in a concentration-dependent manner (Figure 2a-c).

As shown in Figure 3, microscopic evaluation of the morphological changes showed that $\mathrm{H}_{2} \mathrm{O}_{2}$ supplementation in the culture media induced apoptotic cell death characterized by shrinkage of the cell body, whereas treatment with (+)-catechin attenuated $\mathrm{H}_{2} \mathrm{O}_{2}$-induced cell death.

\section{(+)-Catechin inhibits oxidative stress-induced apoptosis in fibroblasts}

To determine whether (+)-catechin has an inhibitory effect on oxidative stress-induced apoptosis in fibroblasts, we assessed the apoptosis of fibroblasts in either the presence or absence of $(+)$-catechin by TUNEL staining. (+)-Catechin $(10 \mu \mathrm{M})$-treated fibroblasts showed significant decreases in the percentage of cells positive for TUNEL staining, compared to vehicle-treated cells $(9.14 \% \pm 0.6 \%$ vs. $1.86 \% \pm 0.3 \%$; Figure 4 ).

\section{Effect of catechin on the activation of caspase- 3 by $\mathrm{H}_{2} \mathrm{O}_{2}$-induced oxidative stress in fibroblasts}

Western blotting analysis using an anti-cleaved caspase-3 antibody showed that the level of cleaved caspase- 3 induced by $\mathrm{H}_{2} \mathrm{O}_{2}$ was reduced by treatment with $10 \mu \mathrm{M}$ (+)-catechin (Figure 5). These results suggest that (+)-catechin inhibits caspase-3-dependent apoptosis induced by oxidative stress in fibroblasts.

\section{(+)-Catechin inhibits phosphorylation of p38 and JNK induced by oxidative stress}

To further investigate the underlying mechanism by which (+)-catechin inhibits oxidative stress-induced apoptosis in fibroblasts, we determined whether oxidative stressinduced phosphorylation of JNK and p38 was inhibited by treatment with $10 \mu \mathrm{M}(+)$-catechin. The results clearly show that $\mathrm{H}_{2} \mathrm{O}_{2}$-induced phosphorylation of p38 and JNK was suppressed by (+)-catechin treatment (Figure 6). 

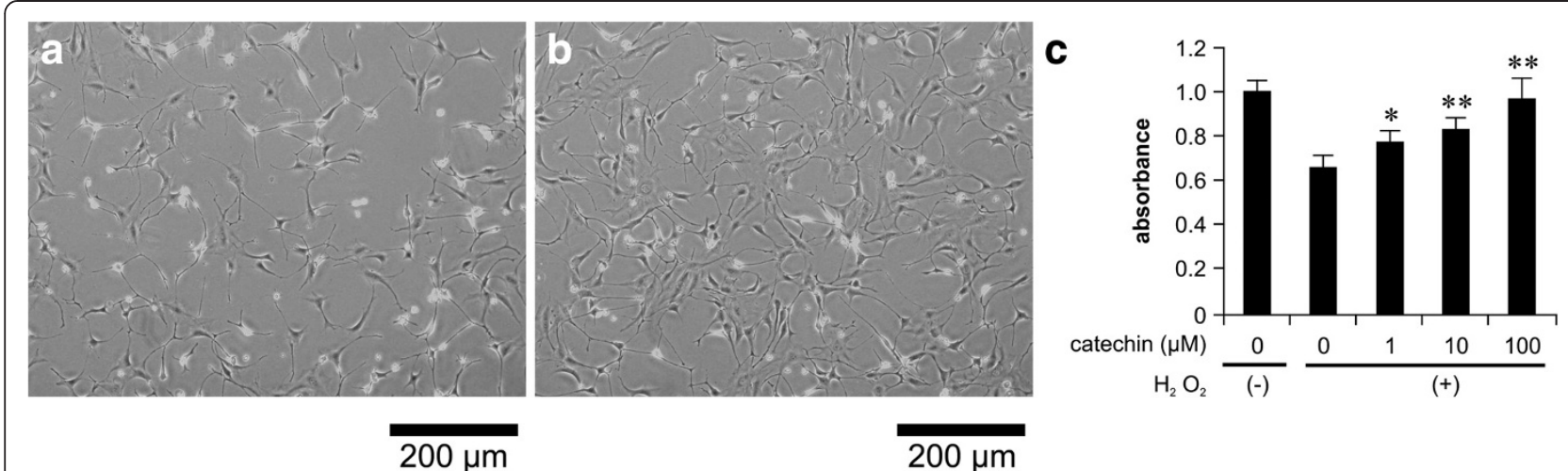

Figure 2 Inhibitory effect of (+)-catechin on oxidative stress-induced cell death in fibroblasts. After incubation with serum-free medium for $24 \mathrm{~h}$, fibroblasts were treated for $30 \mathrm{~min}$ with (+)-catechin (0-400 $\mu \mathrm{M})$ and then subjected to oxidative stress induction with $0.1 \mathrm{mM}$ hydrogen peroxide $\left(\mathrm{H}_{2} \mathrm{O}_{2}\right)$. After $24 \mathrm{~h}$, cell viability was evaluated. (a) Representative microscopic images of cell death induced by oxidative stress (a) and inhibitory effect of (+)-catechin on oxidative stress-induced cell death (b). Cell viability was assessed by the MTT assay (c). Data are expressed as the mean \pm SEM. ${ }^{*} \mathrm{P}<0.05,{ }^{* *} \mathrm{P}<0.01$.

\section{$(+)$-catechin is less cytotoxic than EGCG in fibroblasts} The MTT assay showed that fibroblasts were viable when incubated with high concentrations of $(+)$-catechin. In contrast, EGCG at 200 and $400 \mu \mathrm{M}$ significantly decreased cell viability (Figure 7).

\section{Discussion}

In the present study, we demonstrate an inhibitory effect of $(+)$-catechin on oxidative stress-induced apoptosis in fibroblasts, accompanied by amelioration of the phosphorylation of p38 and JNK induced by oxidative stress.

We focused on fibroblasts because they participate in skin maintenance and renewal. In the skin, fibroblasts play a key role in the production of extracellular matrix components, including collagen, elastin, and hyaluronic acid. In clinical aesthetic medicine, epidermal or intradermal injection of hyaluronic acid is performed to obtain glossy and healthy skin (microinjections of hyaluronic acid, vitamins, minerals, and amino acids into the superficial layer of the skin) [15]. Other techniques, such as implanting activated fibroblasts in the skin, are also known to revive the skin to be glossy and healthy (intradermal injection of cultivated skin fibroblasts into wrinkles) [16-18]. However, these therapies are associated with a high cost and may provoke adverse events, including misplacement, allergy, nodules, necrosis, abscesses, and rejection. In contrast, the use of health supplements, such as green tea and food-derived active substances, is a safer and beneficial anti-aging method.

The integrity and functions of the skin barrier may be impaired by excessive exposure to allergens, chemicals, ultraviolet light, and dehydration. Failure of the skin barrier would subsequently lead to infections with pathogens and result in inflammatory responses. Locally produced reactive oxygen species are also known to inhibit the growth of epithelial cells and fibroblasts by inducing apoptosis and inhibiting collagen and hyaluronic acid production, all of which have been implicated in aging processes leading to skin wrinkles and sagging. Our present study suggests that (+)-catechin is a potential candidate for suppressing oxidative stress-induced apoptosis of skin fibroblasts, which may in turn reverse the reduction of fibroblast-derived

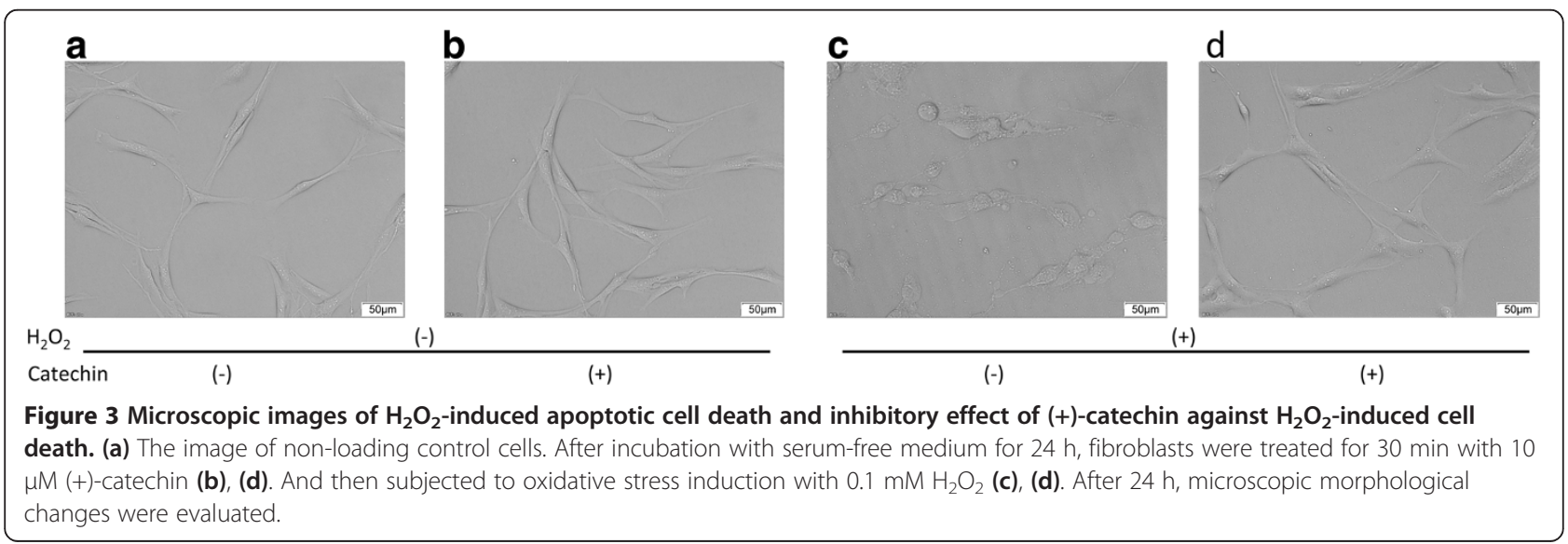




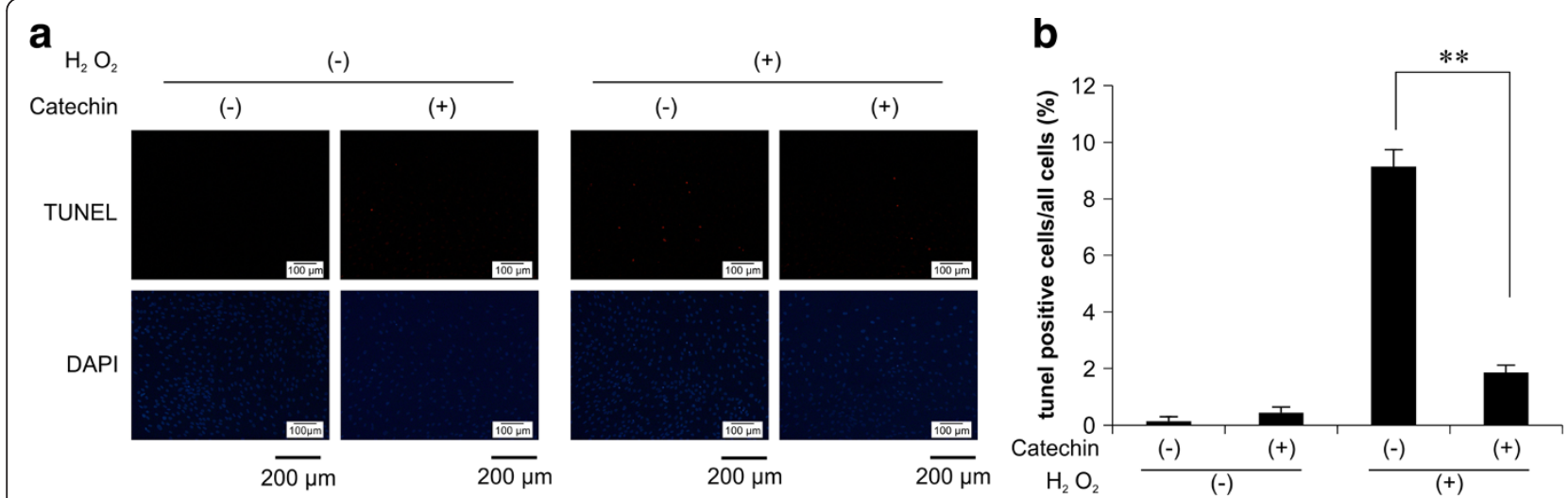

Figure 4 Inhibitory effect of (+)-catechin on oxidative stress-induced apoptosis in fibroblasts. After incubation with serum-free medium for $24 \mathrm{~h}$, fibroblasts were treated for $30 \mathrm{~min}$ with $10 \mu \mathrm{M}(+)$-catechin and then subjected to oxidative stress induction with $0.1 \mathrm{mM}$ hydrogen peroxide $\left(\mathrm{H}_{2} \mathrm{O}_{2}\right)$. After $24 \mathrm{~h}$, apoptosis was evaluated by TUNEL staining. (a) Microscopic findings of TUNEL staining for detection of apoptotic cells. (b) For evaluation of apoptosis, 100 cells were randomly selected and the percentage of TUNEL-positive cells was measured. Data are expressed as the mean \pm SEM. ${ }^{* *} \mathrm{P}<0.01$.

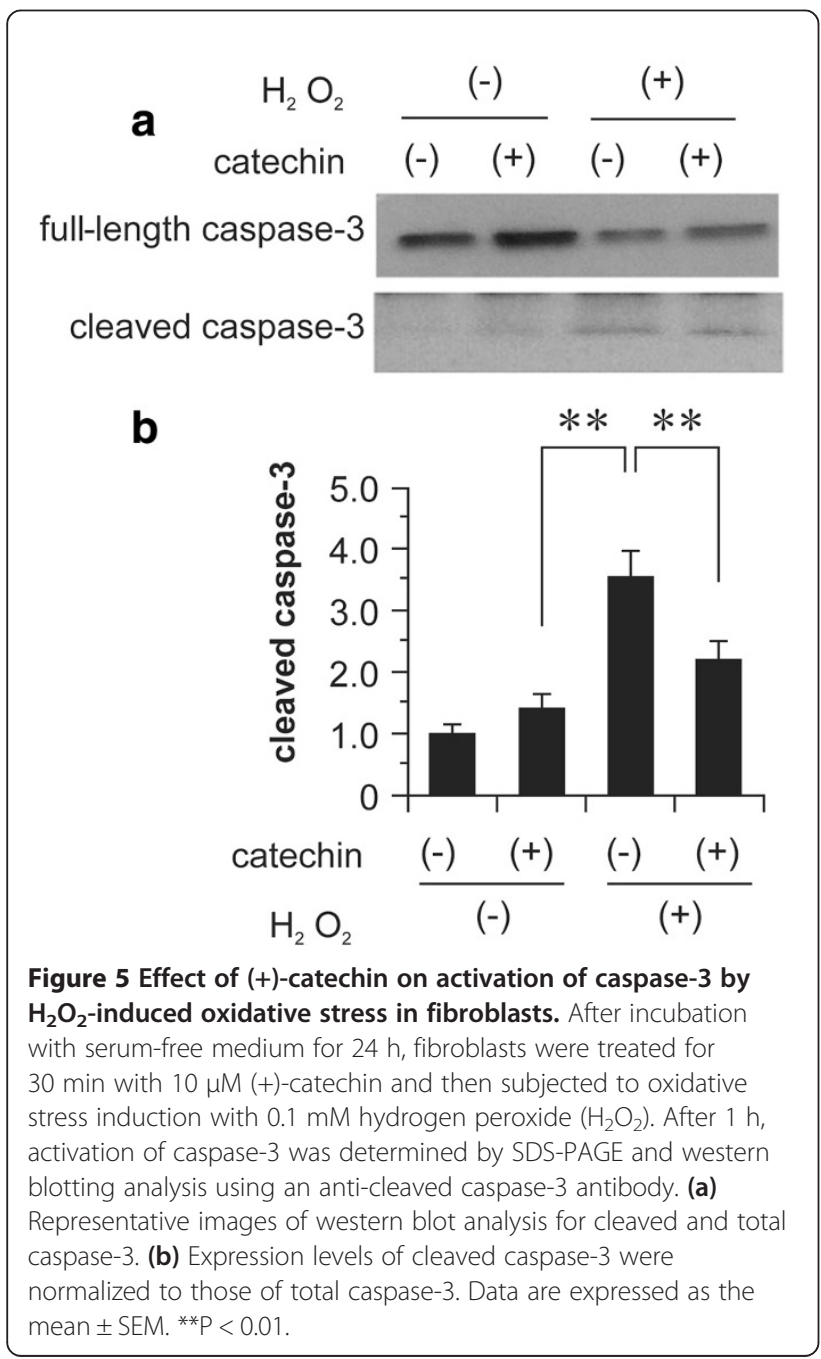

production of collagen and hyaluronic acid. Other reports suggest that EGCG, another type of catechin, is also a potential candidate for suppressing oxidative stress-induced apoptosis of skin fibroblasts [19]; however, our present study showed that $(+)$-catechin is less cytotoxic than EGCG, suggesting that for therapeutic and preventive purposes $(+)$-catechin may be superior to EGCG.

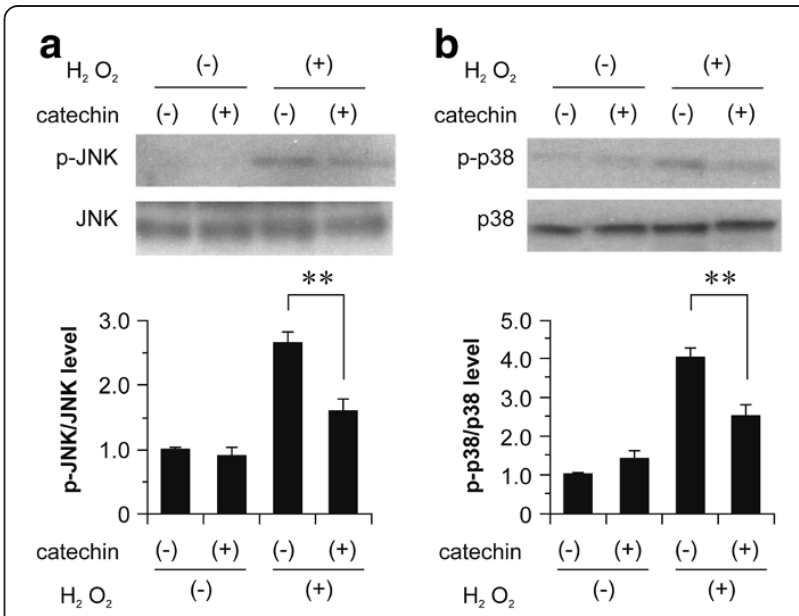

Figure 6 Inhibitory effect of (+)-catechin on phosphorylation of p38 and JNK induced by oxidative stress in fibroblasts. After incubation with serum-free medium for $24 \mathrm{~h}$, fibroblasts were treated for 30 min with $10 \mu \mathrm{M}(+)$-catechin and then subjected to oxidative stress induction with $0.1 \mathrm{mM}$ hydrogen peroxide $\left(\mathrm{H}_{2} \mathrm{O}_{2}\right)$. After $1 \mathrm{~h}$, cells were collected, and phosphorylation of $\mathrm{p} 38$ and JNK was determined by SDS-PAGE and western blotting analysis using anti-phospho p38 and anti-phospho JNK antibodies. (a) Results of western blotting for phosphorylation of (a) p38 and (b) JNK. Phosphorylation levels of p38 and JNK were normalized to those of total p38 and JNK, respectively. Data are expressed as the mean \pm SEM. ${ }^{* * P}<0.01$ 

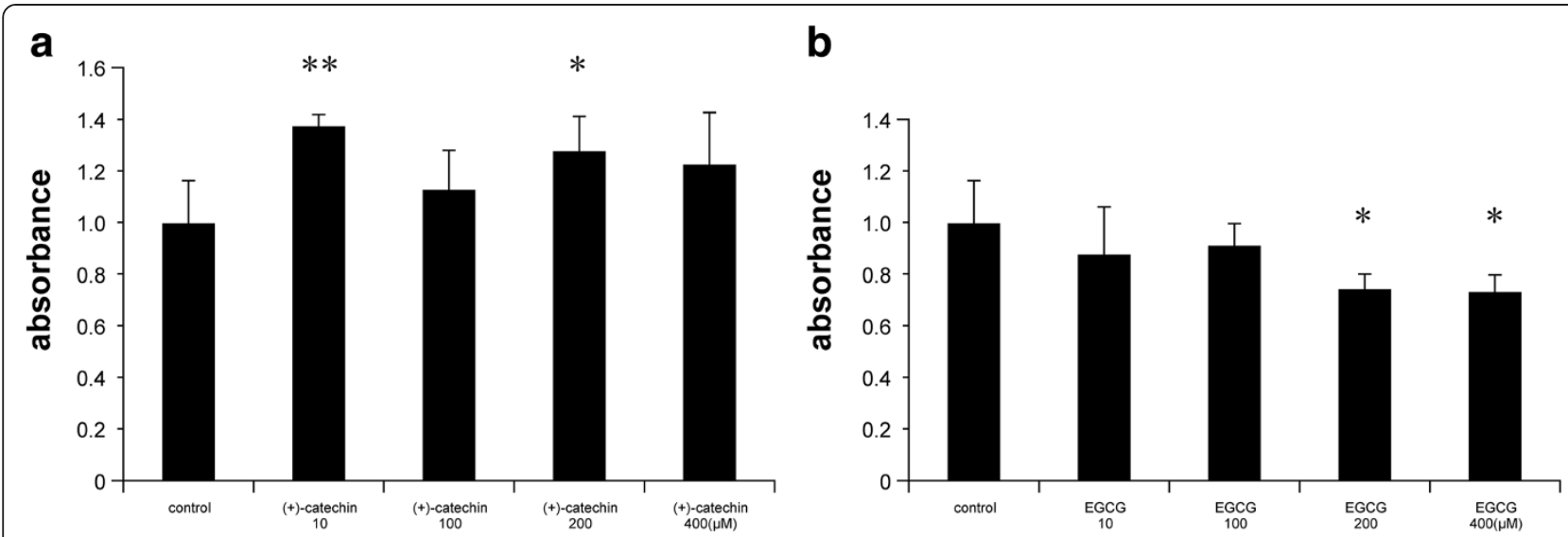

Figure 7 Comparative evaluation of cytotoxicity between (+)-catechin and EGCG in fibroblasts. Fibroblasts were treated with PBS (control) or the indicated concentrations of (a) (+)-catechin and (b) EGCG for $24 \mathrm{~h}$. Cell viability was assessed by the MTT assay. Data are expressed as the mean \pm SEM. ${ }^{* P}<0.05$ and ${ }^{* * P}<0.01$.

To elucidate the underlying mechanisms by which $(+)$-catechin inhibits oxidative stress-induced apoptosis in fibroblasts, we focused on the effects of $(+)$-catechin on the phosphorylation of p38 and JNK, both of which are key molecules for oxidative stress-induced apoptosis [14]. JNK and p38 belong to the family of stress kinases and have been shown to be required for biological stress responses, such as apoptosis induced by UV, radiation, oxidative stress, heat shock, and tumor necrosis factor (TNF)- $\alpha$ stimulation. It has been reported that $\mathrm{H}_{2} \mathrm{O}_{2}$ signaling through TNF receptor 1 selectively activates JNK and p38 $[20,21]$. JNK plays an important role in controlling cell death and is known to affect the function of Bcl-2 family molecules, which suppress apoptosis. Specifically, phosphorylation of Bcl-2 by JNK results in the inhibition of $\mathrm{Bcl}-2$ function and therefore induces the activation of apoptosis [20,21]. In contrast, p38 MAPK is known to be involved in the activation of apoptosismodulating proteins, such as Fas and Bax [21]. Collectively, our present study suggests that (+)-catechin exerts antiapoptotic effects against oxidative stress by inhibiting the phosphorylation of $\mathrm{p} 38$ and JNK. The precise mechanisms by which $(+)$-catechin suppresses the phosphorylation of JNK and p38 will be a future research topic.

Although (+)-catechin was found to exert anti-apoptotic effects in the present study, previous reports have shown both pro-apoptotic and anti-apoptotic effects of catechins. In particular, EGCG, a molecule in the same catechin group, was suggested to play a role in growth inhibition and apoptosis induction in a variety of cancer cells [22]. In contrast, EGCG was reported to have an anti-apoptotic effect in renal mesangial cells [23] and endothelial cells [24], similar to our results in the present study. Therefore, we speculate that the effect of catechins on apoptosis may vary according to cell type and the nature of pathogenesis. Given the different cell-specific responses of catechins, it is important to establish an appropriate strategy for using catechins for treatment and prevention of various diseases. It would be ideal for catechins have suppressive actions against cancers and protective effects for organs such as the kidneys and cardiovascular system. Accumulating evidence on the preventive effect of catechins and green tea against various systemic diseases, including cancers, diabetes, and hypertension, suggests little potential harm to human health from high consumption of catechins and green tea for maintenance of skin beauty.

\section{Conclusions}

$(+)$-Catechin exerts preventive effects against oxidative stress-induced apoptosis in fibroblasts. The underlying mechanism may involve the inhibition of p38 and JNK phosphorylation. As a safe green tea-derived antioxidant, $(+)$-catechin could be suitable for long-term prevention of oxidative stress-induced skin aging, considering the action of skin fibroblasts on the preservation of healthy, youthful skin.

\section{Abbreviations}

EGCG: (-)-epigallocatechin gallate; EGC: (-)-epigallocatechin; ECG: (-)-epicatechin gallate; EC: (-)-epicatechin; JNK: c-Jun terminal kinase MTT, 3-(4,5-dimethylthiazole2-yl)-2,5-diphenyltetrazolium bromide; TdT: Terminal deoxynucleotidyl transferase; TMR: Tetramethylrhodamine; TUNEL: Terminal deoxynucleotidyl transferase (TdT)-mediated dUTP-biotin nick end labeling.

\section{Competing interests}

The authors declare that they have no competing interests.

\section{Authors' contributions}

TT designed and performed the study and wrote the manuscript. SK designed and performed the study and revised the manuscript. RY, TF, TK, $\mathrm{KY}$, and $\mathrm{KH}$ helped to perform the study. TM, YH, KT, KM, KS, SM, and MT provided technical support. All authors read and approved the final manuscript.

\section{Acknowledgements}

This work was supported by the Mishima Kaiun Memorial Foundation. The authors are very grateful to Tetsuya Tanigawa for his advice. 


\section{Author details}

${ }^{1}$ Department of Plastic Surgery, Osaka University Graduate School of Medicine, Suita-shi, Osaka, Japan. ²Department of Child Development and Molecular Brain Science, United Graduate School of Child Development, Osaka University, Suita-shi, Osaka, Japan. ${ }^{3}$ Department of Research \& Development Noevir Co., Ltd. Higashiomi, Shiga, Japan. ${ }^{4}$ Division of Molecular Brain Science, Research Institute of Traditional Asian Medicine, Kinki University, Osakasayama, Osaka, Japan. ${ }^{5}$ Division of Plastic and Reconstructive Surgery, Niigata University Graduate School of Medicine, Niigata-shi, Niigata, Japan.

Received: 24 September 2013 Accepted: 24 March 2014

Published: 8 April 2014

\section{References}

1. Baumann L: Skin ageing and its treatment. J Patho/ 2007, 211:241-251.

2. Fenske NA, Lober CW: Structural and functional changes of normal aging skin. J Am Acad Dermatol 1986, 15:571-585.

3. Callaghan TM, Wilhelm KP: A review of ageing and an examination of clinical methods in the assessment of ageing skin. Part I: Cellular and molecular perspectives of skin ageing. Int J Cosmet Sci 2008, 30:313-322.

4. Rice-Evans CA, Miller NJ, Paganga G: Structure-antioxidant activity relationships of flavonoids and phenolic acids. Free Radic Biol Med 1996, 20:933-956.

5. Valcic S, Muders A, Jacobsen NE, Liebler DC, Timmermann BN: Antioxidant chemistry of green tea catechins. Identification of products of the reaction of (-)-epigallocatechin gallate with peroxyl radicals. Chem Res Toxicol 1999, 12:382-386

6. Ruch RJ, Cheng SJ, Klaunig JE: Prevention of cytotoxicity and inhibition of intercellular communication by antioxidant catechins isolated from Chinese green tea. Carcinogenesis 1989, 10:1003-1008.

7. Higdon JV, Frei B: Tea catechins and polyphenols: health effects, metabolism, and antioxidant functions. Crit Rev Food Sci Nutr 2003, 43:89-143.

8. Cavet ME, Harrington KL, Vollmer TR, Ward KW, Zhang JZ: Anti-inflammatory and anti-oxidative effects of the green tea polyphenol epigallocatechin gallate in human corneal epithelial cells. Mol Vis 2011, 17:533-542.

9. Steinmann J, Buer J, Pietschmann T, Steinmann E: Anti-infective properties of epigallocatechin-3-gallate (EGCG), a component of green tea. Br J Pharmacol 2013, 168:1059-1073.

10. Sharma A, Gupta S, Sarethy IP, Dang S, Gabrani R: Green tea extract: possible mechanism and antibacterial activity on skin pathogens. Food Chem 2012, 135:672-675.

11. Achour M, Mousli M, Alhosin M, Ibrahim A, Peluso J, Muller CD, Schini-Kerth VB, Hamiche A, Dhe-Paganon S, Bronner C: Epigallocatechin-3-gallate up-regulates tumor suppressor gene expression via a reactive oxygen species-dependent down-regulation of UHRF1. Biochem Biophys Res Commun 2013, 430:208-212.

12. Zhang $Y$, Yang ND, Zhou F, Shen T, Duan T, Zhou J, Shi $Y$, Zhu XQ, Shen HM: (-)-Epigallocatechin-3-gallate induces non-apoptotic cell death in human cancer cells via ROS-mediated lysosomal membrane permeabilization. PLoS One 2012, 7:e46749.

13. Fujimura Y, Sumida M, Sugihara K, Tsukamoto S, Yamada K, Tachibana H: Green tea polyphenol EGCG sensing motif on the 67-kDa laminin receptor. PLoS One 2012, 7:e37942.

14. Naderi J, Hung M, Pandey S: Oxidative stress-induced apoptosis in dividing fibroblast involves activation of p38 MAP kinase and over-expression of Bax resistance of quiescent cells to oxidative stress. Apoptosis 2003, 8:91-100.

15. Alster TS, West TB: Human-derived and new synthetic injectable materials for soft-tissue augmentation: current status and role in cosmetic surgery. Plast Reconstr Surg 2000, 105:2515-2525.

16. Eça LP, Pinto DG, de Pinho AM, Mazzetti MP, Odo ME: Autologous fibroblast culture in the repair of aging skin. Dermato/ Surg 2012, 38:180-184.

17. Jäger C, Brenner C, Habicht J, Wallich R: Bioactive reagents used in mesotherapy for skin rejuvenation in vivo induce diverse physiological processes in human skin fibroblasts in vitro- a pilot study. Exp Dermatol 2012, 21:72-75.

18. Solakoglu S, Tiryaki T, Ciloglu SE: The effect of cultured autologous fibroblasts on longevity of cross-linked hyaluronic acid used as a filler. Aesthet Surg J 2008, 28:412-416.

19. Feng B, Fang Y, Wei SM: Effect and mechanism of epigallocatechin-3-gallate (EGCG). against the hydrogen peroxide-induced oxidative damage in human dermal fibroblasts. J Cosmet Sci 2013, 64:35-44.
20. Liu J, Lin A: Role of JNK activation in apoptosis: a double-edged sword. Cell Res 2005, 15:36-42.

21. Wada T, Penninger JM: Mitogen-activated protein kinases in apoptosis regulation. Oncogene 2004, 23:2838-2849.

22. Yang CS, Wang X, Lu G, Picinich SC: Cancer prevention by tea: animal studies, molecular mechanisms and human relevance. Nat Rev Cancer 2009, 9:429-439.

23. Liang YJ, Jian JH, Liu YC, Juang SJ, Shyu KG, Lai LP, Wang BW, Leu JG: Advanced glycation end products-induced apoptosis attenuated by PPAR $\delta$ activation and epigallocatechin gallate through NF-KB pathway in human embryonic kidney cells and human mesangial cells. Diabetes Metab Res Rev 2010, 26:406-416.

24. Choi YJ, Jeong YJ, Lee YJ, Kwon HM, Kang YH: (-)Epigallocatechin gallate and quercetin enhance survival signaling in response to oxidant-induced human endothelial apoptosis. J Nutr 2005, 135:707-713.

doi:10.1186/1472-6882-14-133

Cite this article as: Tanigawa et al:: (+)-Catechin protects dermal fibroblasts against oxidative stress-induced apoptosis. BMC Complementary and Alternative Medicine 2014 14:133.

\section{Submit your next manuscript to BioMed Central and take full advantage of:}

- Convenient online submission

- Thorough peer review

- No space constraints or color figure charges

- Immediate publication on acceptance

- Inclusion in PubMed, CAS, Scopus and Google Scholar

- Research which is freely available for redistribution
Biomed Central 